\title{
A Case of Decreasing Self-esteem Score after Administration of OROS-MPH to a 10-years-old Boy with ADHD
}

\author{
Junichi Furusho ${ }^{1^{*}}$, Yusuke Isozaki ${ }^{2}$ and Kumiko Matsuzaki ${ }^{3}$ \\ ${ }^{1}$ Collage of Education Psychology and Human Studies, Department of Education, Aoyama Gakuin University, Japan \\ ${ }^{2}$ Graduate School of Education, Psychology and Human Studies, Department of Education, Aoyama Gakuin University, Japan \\ ${ }^{3}$ Atomi University, Faculty of Letters, Department of Clinical Psychology, Japan
}

*Corresponding author: Junichi Furusho, Collage of Education Psychology and Human Studies, Department of Education, Aoyama Gakuin University, 4-4-25, Shibuya, Shibuya-ku, Tokyo. 150-8366, Japan, Tel: +81-3-3409-8624; Fax: +81-3-3409-7906; E-mail: furujun@ephs.aoyama.ac.jp

Received: Mar 25, 2014; Accepted: May 03 2014; Published: May 132014

Copyright: () 2014 Junichi F, et al. This is an open-access article distributed under the terms of the Creative Commons Attribution License, which permits unrestricted use, distribution, and reproduction in any medium, provided the original author and source are credited.

\begin{abstract}
We reported a case of decreasing self-esteem score after administration of OROS-MPH to a 10-years-old boy with ADHD. Using ADHD-RS-IV score before and 3 months after MPH medication, his mother and the homeroom teacher did the evaluation and behavioral improvement was confirmed. They both agreed his behaviors that we actually observed in the examination room had been improved. We have simultaneously examined total QoL and scores of each six domains in the Japanese version of Kid-KINDLR (age 7-13) questionnaire before and 3 months after the administration of MPH medication by himself and his mother. Although evaluation by the parent was unchanged between two evaluations in this case, his own evaluation of $\mathrm{QoL}$ fell down after medication. The domains contributed in a major way to the total QoL decrement were self-esteem and family.
\end{abstract}

We surmised the self-discernment was explained that relationship between him and others could have become very clear by taking OROS-MPH. Although the self-esteem score of subjective self fell down, it became the almost same level as the scores of other children in the same age in Japan, and we think it is rather a normal mental development.

Keywords Attention Deficit/Hyperactivity Disorder (ADHD); Methylphenidate (MPH); Self-esteem; Quality of life; Kid-KINDLR questionnaire

\section{Introduction}

Methylphenidate hydrochloride (MPH) improves Attention Deficit/ Hyperactivity Disorder (ADHD) symptoms, but it is not clear to improve the quality of life (QoL) in patients with $\mathrm{ADHD}$ simultaneously. In the previous studies, Atomoxetine (ATX) demonstrated to improve ADHD symptoms, but the relationship between QoL and ADHD symptoms was unclear [1,2].

To evaluate the effect of osmotic release oral system MPH (OROS$\mathrm{MPH}$ ) on ADHD symptoms and QoL in Japanese children with ADHD, we use ADHD-rating scale-IV (ADHD-RS-IV) to homeroom teachers and parents. As a health-related QoL, we used the Japanese version of Kid-KINDLR (for age 7-13) questionnaire and Japanese parents version of KIDLE (for age 7-16) before and after administering OROS-MPH [3].

The KINDL questionnaire is a short, validated tool comprising 24 items, with six domains (physical wellbeing, emotional wellbeing, selfesteem, family, friends and school). There are 3 different self-reported versions were used according to the age groups, and 2 different versions for parents of patients. Scores were given such that the range of possible values for the sub-scores and the total score was from 0 (most negative state) to 100 (most positive state). Shibata et al. have translated these versions for Japanese and confirmed their reliability and validity [4].

In this study, we report a case of a 10-years-old boy with ADHD who is using OROS-MPH. His ADHD symptoms improved clearly, but the QoL by Kid-KIDLE decreased, especially the self-esteem score after administering OROS-MPH.

For privacy protection, we masked details in the report and informed consent was obtained from the family, and consent of the ethics committee of the affiliated organization has been obtained.

\section{Case Report}

A 10 years old boy was not calming and is restless in both at home and in school. Before the medication was given, he was always moving in the examination room and the reception room. For example, he was violently shaking the desk by hands during the examination. He also suddenly started running to the shop in the hospital, took a bottle of beverage, and then he noticed that he didn't have money. We tried to ask what his state was, but he didn't listen to the end of the question and made an instant reply. His answers were very simple, such as "yes", "no", or "no problem".

So we diagnosed him as ADHD and administrated OROS-MPH $18 \mathrm{mg}$ per day after the informed consent was signed. After the administration, he was able to listen to our question to the end and to use polite words. His mother reported that her son said, "I can become a good person if I take the medicine". Three months later, he said, "I became a good boy. My next target is to stay good without the medicine but I am not very confident now." 
When his homeroom teacher asked him to change seat, he explained that he was just doing the best by taking medicine, that he would stop violent behaviors, and asked the teacher to accept him.

Table 1 shows the change of ADHD-RS-IV scores before and 3 months after MPH medication by his mother and the homeroom teacher. The scores show improvements, and they are in line with our evaluation in the examination room.

\begin{tabular}{|l|l|l|l|l|}
\hline \multirow{2}{*}{} & \multicolumn{2}{|l|}{ Mother } & \multicolumn{2}{l}{ Homeroom teacher } \\
\cline { 1 - 4 } Score (\%tile) & Before & After & Before & After \\
\hline IA & $18(96 \%)$ & $16(95 \%)$ & $17(75 \%)$ & $11(50 \%)$ \\
\hline HI & $22(98 \%)$ & $9(80 \%)$ & $23(91 \%)$ & $20(87 \%)$ \\
\hline Total & $40(97 \%)$ & $25(90 \%)$ & $40(86 \%)$ & $31(75 \%)$ \\
\hline
\end{tabular}

Table 1: Changing of ADHD-RS-IV Score Before/After; IA: Inattention; HI: Hyperactivity Impulse

Figure 1 shows the change in Total QoL and each of the six domains scores between before and 3 months after MPH medication evaluated by himself and his mother. Although evaluation by the parents' version of Kid-KINDL was unchanged, his evaluation of QoL fell down after medication in this case. The domains contributed in a major way to the total QoL decrement were self-esteem and family.

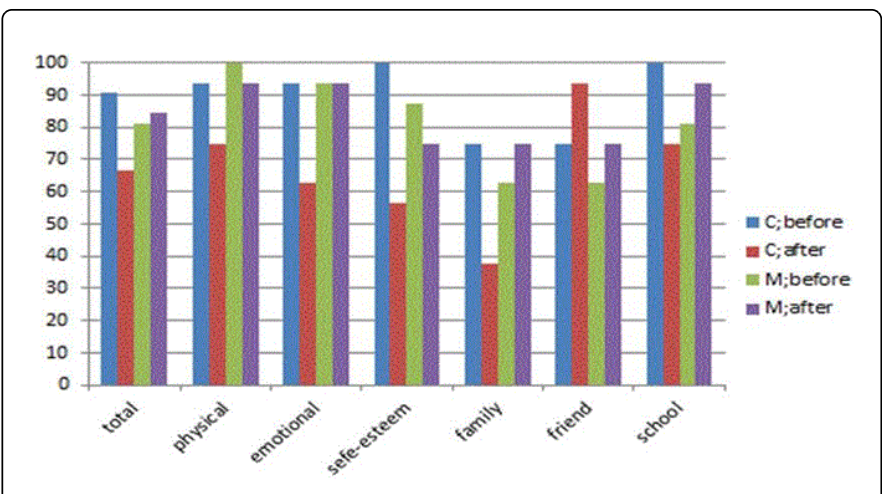

Figure 1: Change in Total QoL and Each Domains Scores between before/After medication; C: Case; M: Mother; Physical: Physical wellbeing; Emotional: Emotional wellbeing

\section{Discussion}

Children with ADHD experience difficulty in various scenes of usual life, and their symptoms affect their social functions and QoL.

Dupaul et al. developed ADHD-RS-IV, and it is widely used for diagnosis and evaluation of ADHD [5]. Efficacy about QoL is assessed using Strengths and Difficulties Questionnaire (SDQ) [6], and Child Health Questionnaire (CHQ) [7].

Until now, the link between the reduction of ADHD symptoms and concurrent, drug-specific improvements in functional outcomes has been established. Previous studies have demonstrated improvement of ADHD core symptoms only. Functional failure by ADHD such as in family and school environment in daily life isn't considered even today.

In Japan, permissible medicine for ADHD is only one kind of MPH, which is OROS-MPH, and ATX. Permission of the both medicines in Japan started several years ago. Therefore, there are only few reports on the effect of the medicines, and there is no paper about whether MPH improves QoL or not for Japanese patients.

Although ADHD symptoms improved clearly after $\mathrm{MPH}$ medication in this case, the patient's measurement of QoL by the Japanese version of Kid-KINDLR (age 7-13) questionnaire fell down. Especially the fall of self-esteem and the family domains were conspicuous. Rothenberger et al. [8] reported that ADHD has a major impact on patient QoL, and using treatment options accepted by patients may represent an effective strategy to improve QoL. They also used KINDL questionnaire, but their conclusion seemed to be opposite to our case [8].

As this factor, we speculated that the change in his language and behavior in the examination room was result of him started recognizing and understanding existence of others. We surmised that the self-discernment and the relationship between him and others could have become very clear by taking OROS-MPH. Although the self-esteem score of subjective self fell down, it became almost same level as the scores of other children in the same age in Japan, and we think it indicates rather a normal mental development $[3,9]$.

The decrement of the score in the family domain could have come from dissatisfaction for his parents did not value his efforts. This was also related to realizing others' recognition, and we think that this conflict between his parents indicates improvement.

We are going to examine to analyze more Japanese ADHD cases.

\section{References}

1. Spencer T, Biederman J, Wilens T, Harding M, O'Donnell D, et al. (1996) Pharmacotherapy of attention-deficit hyperactivity disorder across the life cycle. J Am Acad Child Adolesc Psychiatry 35: 409-432.

2. Brown RT, Perwien A, Faries DE, Kratochvil CJ, Vaughan BS (2006) Atomoxetine in the management of children with ADHD: effects on quality of life and school functioning. Clin Pediatr 45: 819-827.

3. Furusho J, Kubagawa T, Satoh H, Shibata R, Nemoto Y, et al. (2003) A Study of the Kid-KINDL Questionnaire for Measuring Quality of Life in Elementary School children in Japan. Nihon-Shonikagakukai-Zassi 107: 1514-1520.

4. Ravens-Sieberer U, Bullinger M (1998) Assessing health-related quality of life in chronically ill children with the German KINDL: first psychometric and content analytical results. Qual Life Res 7: 399-407.

5. Dupaul GJ, Power TJ, Anastopoulos AD, Reid R (Eds) (1998) ADHD Rating Scale--iv: Checklists, Norms, and Clinical Interpretation. Guilford Publications, New York.

6. Döpfner M, Steinhausen HC, Coghill D, Dalsgaard S, Poole L, et al. (ADORE Study Group) (2006) Cross-cultural reliability and validity of ADHD assessed by the ADHD Rating Scale in a pan-European study. Eur Child Adolesc Psychiatry 1: 146-155. Erratum in (2009) Eur Child Adolesc Psychiatry $18: 194-196$.

7. Perwien AR, Faries DE, Kratochvil CJ, Sumner CR, Kelsey DK, et al. (2004) Improvement in health-related quality of life in children with ADHD: an analysis of placebo controlled studies of atomoxetine. J Dev Behav Pediatr 25: 264-271.

8. Rothenberger A, Becker A, Breuer D, Döpfner M (2011) An observational study of once-daily modified-release methylphenidate in ADHD: quality of life, satisfaction with treatment and adherence. Eur Child Adolesc Psychiatry 20: 257-265. 
Citation: Furusho J, Isozaki Y, Matsuzaki K (2014) A Case of Decreasing Self-esteem Score after Administration of OROS-MPH to a 10-yearsold Boy with ADHD. J Psychol Abnorm Child 3: 116. doi:10.4172/2329-9525.1000116

Page 3 of 3

9. Furusho J, Isozaki Y (2013) Study of self-reported QoL scores using Japanese version of Kid-KINDLR (age7-13) questionnaire for children with developmental disorders. Aoyamagakuindaigaku-kyouikugakkaikiyou-kyouikukenkyu 58: 97-110. 